\title{
El secreto de la composición: el Kosmos de Humboldt como espacio postcolonial
}

\author{
Oliver Lubrich ${ }^{1}$
}

Recibido: 1 de diciembre de 2016 / Aceptado: 22 de febrero de 2017

Resumen. Alexander von Humboldt ganó celebridad gracias a su viaje por América (entre 1799 y 1804). Una amplísima divulgación alcanzó su obra Kosmos, una descripción en cinco volúmenes (1845-1862) acerca del estado de conocimientos sobre el mundo. En un capítulo clave (1847), Humboldt expone la historia del saber como una historia de la violencia. Desde la Antigüedad clásica, el autor reconoce la existencia de una dialéctica entre la exploración científica del mundo y su explotación imperialista. Concebido después de las revoluciones independentistas latinoamericanas, Kosmos es la primera contribución de la literatura alemana a la teoría postcolonial. Desde esa perspectiva política puede entenderse también la híbrida forma de la obra. A partir del capítulo sobre la historia del conocimiento, el Kosmos desarrolla una confusa proliferación de distintos formatos y sub-formatos que parece imitar la exuberancia de la vegetación tropical. La disolución de una forma sistemática, "imperial", es el efecto de esa mirada crítica al carácter colonial de las ciencias.

Palabras clave: Alexander von Humboldt; Kosmos; historia de la ciencia; imperialismo; teoría postcolonial.

\section{[en] The Secret of Composition. Humboldt's Cosmos as a Post-Colonial Space}

\begin{abstract}
Alexander von Humboldt became world-famous during his American voyage (1799-1804). His last and most popular book, Kosmos, represents the entire world in five volumes (1845-1862). In a key chapter (1847) Humboldt narrates the history of knowledge as a history of violence. He diagnoses a dialectics of exploration and appropriation since Greek and Roman Antiquity. Conceived after the Latin American Revolution of Independence, Kosmos is the first contribution of German literature to post-colonial theory. From this political perspective, we can even understand the hybrid poetics of Humboldt's work. In Kosmos, a large number of formats and sub-formats confusingly proliferate, apparently imitating tropical vegetation. This dissolution of a systematic, centered form, following the recognition of research as a colonial activity, however, is rather the effect of Humboldt's self-critical insight into the connection between Science and Empire. He gave up the project of authorially representating the world, and instead artistically demonstrated its failure.
\end{abstract}

Keywords: Alexander von Humboldt; Kosmos; History of Science; Imperialism; Post-colonial Theory.

1 Universität Bern

E-mail: oliver.lubrich@germ.unibe.ch 
Sumario. 1. Composición. 2. Prosa tropical. 3. Historia colonial del saber. 4. La "expedición de Alexander". 5. Homonimia. 6. Metáforas del colonialismo. 7. Poética postcolonial.

Cómo citar. Lubrich, O., «El secreto de la composición: el Kosmos de Humboldt como espacio postcolonial», Revista de Filología Alemana 25 (2017), 25-44.

He has aimed to present to others what nature presented to him, combinations interlocked in such a complicated way as hardly to be distinguishable, and his writings present something of the kind.

Louis Agassiz, Eulogy (1859) ${ }^{2}$

Who, out of the theory of the earth, and of his or her body, understands by subtle analogies, the theory of a city, a poem, and of the large politics of These States.

Walt Whitman, Kosmos $(1860)^{3}$

Das Gelangen zu den einfachsten Erfindungen und Grundsätzen hat Millionen das Leben gekostet, die auf dem Wege starben.

Georg Büchner, Dantons Tod (1835) ${ }^{4}$

"In einem vielumfassenden Werke, in dem Leichtigkeit des Verständnisses und Klarheit des Totaleindrucks erstrebt werden, sind Composition und Gliederung in der Anordnung des Ganzen fast noch wichtiger als die Reichhaltigkeit des Inhalts" (Humboldt 1845-1862: IV, 3$)^{5}$. Con esas palabras, que inauguran el cuarto volumen de Kosmos (1858), Alexander von Humboldt indica a sus lectores la significación que distingue a la concepción literaria de su libro. La forma ha de ser "fast noch wichtiger" que el contenido. Y eso, ¿en un libro de ciencia? Mediante el uso del comparativo ("wichtiger"), su énfasis ("noch") y su restricción retórica ("fast"), Humboldt subraya lo inusual de su afirmación.

No obstante, hasta ahora apenas se ha tenido en cuenta la forma de esta obra ${ }^{6}$, que tampoco ha sido analizada aún desde un punto de vista político. Sin embargo,

2 "Intentó presentar a otros lo que la naturaleza le presentaba a él: combinaciones entrelazadas de un modo tan complicado que eran casi indistinguibles, y sus escritos presentan algo parecido" (Agassiz 1859: 105).

3 "Quién, hombre o mujer, con la teoría de la tierra y de su cuerpo comprende por sutiles analogías la teoría de una ciudad, un poema y de la vasta política de estos Estados" (Whitman 1860-1861: 414-415).

4 Saint-Just: "Llegar a los inventos y principios más sencillos les ha costado la vida a millones que murieron por el camino" (Büchner 1988: 65).

5 "En una obra que abarca muy variados aspectos, en la que se aspira a la facilidad del entendimiento y la claridad de la impresión general, la composición y la estructuración en el orden del todo resultan casi tanto más importantes que la diversidad del contenido". Todas las citas de Kosmos han sido tomadas de la edición original. Los números romanos remiten al tomo, los arábigos (o los números romanos usados en el prefacio) a la página. Versión revisada y reelaborada de Lubrich (2014), traducido del alemán (así como las citas del alemán, inglés o francés) por José Aníbal Campos.

6 Una significativa excepción la constituye el capítulo sobre Alexander von Humboldt en el libro de Hans Blumenberg Die Lesbarkeit der Welt (1981), de la que hablaremos más adelante. La primera reedición no 
Kosmos encierra el intento más temprano de la literatura alemana por escribir una historia sistemática y crítica del colonialismo y por dotar a esa historia, a su vez, de una forma artística. ¿Cuáles son, por lo tanto, la "composición”, la "estructuración" y el "orden" de los que habla el autor? ¿Qué relación se establece entre la forma del Kosmos y su contenido, la imagen del mundo y su exploración? Para ilustrar el vínculo sutil existente entre la poética y la política y poder leer la forma literaria de Kosmos desde una perspectiva postcolonial, debemos partir de una descripción exacta del texto: un texto con el que ocurre algo insólito a lo largo de su desarro$110^{7}$.

\section{Composición}

No resulta tarea sencilla obtener una visión general de la estructura de este opus maximum. En su contenido, el texto puede describirse como una sucesión de cinco partes que no coinciden con la división en cinco tomos: a (1) la introducción programática (en tres secciones) $)^{8}$ le sigue, en el primer tomo, (2) una primera presentación general del universo, primeramente del cielo y luego de la Tierra ("kleines Naturgemälde") ${ }^{9}$ que más tarde se aborda en el segundo tomo (3) en su relación con las artes (literatura, pintura, jardinería) ${ }^{10}$ y (4) es tratado en su evolución histórica $^{11}$, antes de ofrecer en los últimos tres tomos (5) una nueva y mucho más amplia presentación general del universo ("großes Naturgemälde"), una vez más con una presentación, primero, del cielo (tercer tomo) ${ }^{12}$ y luego de la Tierra (cuarto tomo y el fragmento del quinto tomo) ${ }^{13}$. Aparte de las secciones teóricas, artísticas e históricas, Humboldt emprende una descripción física del mundo que ha sido anunciada ya por su subtítulo, de modo que la presenta, didácticamente, dos veces: en un resumen abreviado (415 páginas) y en otro más extenso (1.385 páginas): en una especie de micro-Kosmos y de macro-Kosmos ${ }^{14}$.

Más curiosa que esta concepción redundante y a gran escala es, sin embargo, la refinada estructura más detallada. Alexander von Humboldt divide su obra no solo en cinco partes, (1) Teoría, (2) Pequeño cuadro de la naturaleza, (3) Historia de las artes, (4) Historia de las ciencias y (5) Gran cuadro de la naturaleza, así como en cinco tomos, cuya publicación se extiende a lo largo de los años 1845, 1847, 1850, 1858 y (póstumamente) 1862, sino que la estructuró en numerosas secciones, capítulos y subcapítulos de diferente orden en los que los pasajes individuales quedan asimismo subdivididos con subtítulos, cifras o letras, de un modo bastante imbrica-

abreviada de Kosmos desde el siglo XIX, en la que podría estudiarse la forma del libro, no apareció hasta el siglo XXI (Humboldt 2004).

7 Existen tres traducciones del Kosmos de Humboldt al español (Humboldt 1851-1852; Humboldt 1874-1875; Humboldt 2011).

8 "Vorrede" (I, V-XVI), "Einleitende Betrachtungen über die Verschiedenartigkeit des Naturgenusses und eine wissenschaftliche Ergründung der Weltgesetze" (I, 3-48), "Begrenzung und wissenschaftliche Behandlung einer physischen Weltbeschreibung" (I, 49-78).

9 "Naturgemälde. Allgemeine Uebersicht der Erscheinungen" (III, 79-493).

10 “Anregungsmittel zum Naturstudium" (II, 3-134).

11 "Geschichte der physischen Weltanschauung" (II, 135-520).

12 "Specielle Ergebnisse der Beobachtung in dem Gebiete kosmischer Erscheinungen" (III).

13 "Specielle Ergebnisse der Beobachtung in dem Gebiete tellurischer Erscheinungen" (IV, V, 3-98).

14 Sobre el programa de Kosmos que Humboldt no consiguió llegar a realizar, véase Lubrich (2006: 39-54). 
do. Abundan las tablas, las notas, las notas adicionales, los añadidos y las correcciones, aparte de las listas con fe de erratas y una sinopsis dedicada a un atlas, cuya estructura, al menos en parte, coincide con el Kosmos que ilustra ${ }^{15}$.

Desde el punto de vista formal, el texto, con sus diversos sub-formatos, tiene catorce niveles. Sus elementos individuales están dotados de signos o se las arreglan sin codificaciones numéricas o alfabéticas. En total hay once marcas tipográficas distintas cuya jerarquía apenas puede identificarse mediante una regularidad continua: números arábigos (en tres niveles), números romanos en mayúscula (en dos niveles), letras del alfabeto latino en minúsculas (en dos niveles) y en mayúscula (en dos niveles), así como letras griegas en minúsculas (en dos niveles) ${ }^{16}$.

Los lectores, ante una obra de esta envergadura, quedarían a merced de cierta transparencia en la división, sobre todo si se tiene en cuenta que en el original no hay ninguna columna de títulos que faciliten la orientación. El hecho de que Humboldt haya aludido expresamente a la importancia de la "Composition" (IV, 3), gana una relevancia adicional cuando consideramos la segunda acepción contemporánea de esa palabra: la grafía de los tipos ${ }^{17}$. El caso es que ni siquiera la tipografía se emplea aquí de manera concluyente. Los titulares no solo muestran distintos tamaños, sino varias tipografías, variadas, a su vez, mediante clausuras y engrosamientos, que no dejan entrever un método consistente que nos permita identificar con facilidad la jerarquía de los capítulos ${ }^{18}$. Kosmos no tiene un "sistema orientativo" consistente. Humboldt varía, de manera confusa, la nomenclatura, el orden de rango, la secuencia de sus elementos estructuradores de un tomo a otro. Por ejemplo, en el cuarto tomo cambia la denominación de los subcapítulos de quinto y sexto orden en relación con el tomo tercero, empleando letras griegas en minúscula en lugar de letras latinas en mayúscula, así como números romanos en lugar de arábigos.

Pero sobre todo puede observarse, entre los dos primeros y los tres últimos tomos, una creciente diferenciación en la variedad de los formatos: mientras que el tomo I tiene solo dos niveles distintos desde el punto de vista numérico o alfabético y el tomo II cuenta con tres, en el tomo III esa cantidad se ha ampliado a siete, a seis en el tomo IV y a tres niveles principales en el tomo $\mathrm{V}$, que solo contiene un fragmento de 96 páginas salido de la pluma de Humboldt. Los respectivos títulos principales, entre-títulos y subtítulos, dividen la superficie del texto con una frecuencia cada vez mayor: mientras que los tomos I y II en su conjunto solo mues-

15 "Physikalischer Atlas von Dr. H[einrich] Berghaus" (II, 545-550). Véase "Zu diesem Kartenwerk" Ette/Lubrich (2004: IX-XIII).

16 "Die andere Reise durch das Universum" (Ette/Lubrich 2004: 910-912).

17 Las indicaciones en torno a la historia de la tipografía las debemos a Thomas Nehrlich (Berna).

18 Una carta a Varnhagen von Ense del 15 de abril de 1828 documenta que Humboldt había estado meditando acerca del diseño tipográfico del libro: "Wie soll ich den Titel einrichten. 'Entwurf einer phys. W. von A. v. H. (auf Veranlassung von Vorlesungen neubearbeitet', oder: 'theilweise nach Vorlesungen bearbeitet.')? Alles das scheint mir unbeholfen. Adverbia sind unpassend für Titel. Wie wenn ich mit ganz kleinen Lettern zusetzen ließe: 'Ein Theil dieser Schrift ist der Gegenstand von Vorlesungen in den Jahren 1827 und 1828 gewesen'? Aber das ist lang, und dann das Verbum! 'Auf Veranlassung' ist vielleicht noch besser” "“Cómo podría disponer el título: 'Ensayo de una fís[ica] d[escripción] d[el] m[undo], de A. v. H.' ('revisado a partir de conferencias' o 'elaborado en parte a partir de conferencias')? Todo esto me parece torpe. Los adverbios no son apropiados para los títulos. ¿Y si añadiera con letras muy pequeñas: 'Una parte de este escrito ha sido objeto de conferencias en los años 1827 y 1828'? Pero, es muy largo. ¡Y luego está el verbo! 'A partir' sea tal vez mejor") (Humboldt 1860: 4). 
tran 18 cortes (cuatro en el tomo I y catorce en el tomo II), los tomos III y IV están subdivididos en 94 ocasiones (el tomo III tiene 58 partes y el tomo IV 36; el fragmento del tomo $\mathrm{V}$, por su parte, tiene seis). La obra, por lo tanto, tiene una división sumamente variada y ello cambia cualitativa y cuantitativamente a lo largo de los tomos individuales. Kosmos se inicia con una sencilla serie de partes que, en el tomo II, se dividen de manera simple y sistemática, pero que después, en los tomos III, IV y V, proliferan de una manera caótica.

A veces no es posible seguir la división sin más, y apenas se puede reconocer con certeza a qué categoría deberían pertenecer determinadas partes o en qué nivel del texto y en qué sub-división nos encontramos. Vemos así, por ejemplo, cómo en los tomos III y IV reaparece inesperadamente la misma nomenclatura en un pasaje de un nivel inferior, la misma que ya había sido introducida en un nivel superior, de modo que, a la hora de precisar, el lector no ve con claridad a cuál de las dos series debe pertenecer esa sección, ya que se ofrecen varias opciones de secuencia. En una ocasión se trata del número "III" (tomo IV, 377), que da continuidad a los números I y II de la serie en curso o de la serie superior; y en otra, de manera análoga, se trata de la letra "B" (tomo III, 426), que podría ser la continuación de dos series distintas. Se producen, pues, irritantes duplicaciones.

Esta compleja estructura tiene implicaciones genéricas. La forma homogénea con la que el libro había comenzado se pierde. La escritura se aleja de los formatos convencionales que habían iniciado el primer tomo: como memoria autobiográfica en la "Vorrede" ("Ich übergebe am späten Abend eines vielbewegten Lebens [...]" $\left.(\mathrm{I}, \mathrm{V})^{19}\right)$, como conferencia ("Rede") que finge oralidad en las "Einleitende Beobachtungen" (I, 4) y como ensayo en el primer capítulo teórico ("Begrenzung und wissenschaftliche Behandlung einer physischen Weltbeschreibung" $\left.(\mathrm{I}, 49)^{20}\right)$. La estructura, además, tiene consecuencias de tipo científico: la lógica sistemática de la investigación se disuelve. El intento de una 'medición' del mundo se revela como irrealizable. Y también adquiere, con ello, una dimensión política que resulta menos evidente.

\section{Prosa tropical}

En la medida en que Humboldt divide su obra, dificulta a sus lectores la orientación dentro de la misma. ¿Por qué hace esto? ¿Y por qué su forma evoluciona de ese modo en el transcurso de la obra? Aaron Sachs ha ofrecido una explicación simple: con una alusión biográfica, se remite a la edad de Humboldt: "his poetical side had dried up". En términos psicológicos, habla de una supuesta depresión: "melancholy had overtaken him" (Sachs 2006: 102) ${ }^{21}$.

¿Hay, aparte de éstos, otros motivos que puedan ser propios del objeto mismo de estudio? Alexander von Humboldt se mostró repetidas veces como el partidario de una decidida conciencia formal. ¿Había cometido él, precisamente, "algún error en el orden", tal y como lo había criticado en la Historia naturalis de Plinio, el más importante precursor de su proyecto (II, 230-231)? La crítica de Humboldt a Plinio,

\footnotetext{
19 "Entrego, en el crepúsculo tardío de una vida muy agitada [...]".

20 "Delimitación y el trato de una descripción física del mundo".

21 "Su lado poético se ha marchitado, la melancolía lo ha vencido".
} 
sin embargo, se refiere de un modo concreto y preciso no a meras irregularidades formales, sino al profundo desorden de los contenidos que él había identificado en aquella obra de la Antigüedad ("Mangel[] eines inneren Zusammenhangs der Theile", "die Elemente [...] fast ungeordnet vertheilt" ${ }^{22}$ ). Una crítica, por demás, que apenas podríamos hacerle a su obra ${ }^{23}$. Humboldt indica expresamente que la forma elegida por él va a asombrar a algunos lectores, pero que ésta responde a una concepción bien meditada: existe "[v]ieles, das man nach anderen Ansichten der Composition eines Buches von der Natur, als die meinigen sind, hier vermissen kann" (II, 398) ${ }^{24}$. Una vez más se habla de una "Composition", es decir: de un proyecto intencionado.

Pero, ¿acaso esa "composición" ha fallado? ¿El autor se ha dejado llevar por ciertos manierismos? ¿Se ha extraviado en infinidad de arabescos? ¿O se ha aventurado en un experimento que, sencilla y llanamente, salió mal? ¿No consiguió dominar el material? Su presentación no debía ser ni demasiado general ni demasiado concreta, no debía elevarse en especulaciones teóricas ni perderse en detalles especializados, sino ofrecer el todo en su compleja red de relaciones, con el saber y los métodos de todas las disciplinas disponibles, no siguiendo un método hegeliano-sistemático, sino vivo, natural, adaptado a una forma, además, que poseyera calidad estética. ¿Podía materializarse ese programa?

¿Acaso el objetivo de popularizar una investigación multidisciplinaria ${ }^{25}$, vinculando la ciencia y la estética, era, en principio, irrealizable, de modo que el proyecto solo podía conducir a un fracaso literario, como ha explicado Hartmut Böhme en relación con el libro Ansichten der Natur ("accidente textual"), un fracaso como escritor que se expresa en una descomposición de la arquitectura de la obra? (Böhme 2001: 25).

¿Fracasó Humboldt en su presentación de Kosmos? A primera vista, sí. Pero solo a primera vista. Porque, ¿habría tenido otra opción? ¿Debió estructurar el mundo de un modo más racional? ¿Habría sido un orden más claro lo apropiado para su objeto de estudio? El científico no reduce el mundo que representa a un esquema artificial que finja una visión panorámica donde no puede haberla, afirmando, de ese modo, una sistematicidad engañosa. El autor sigue empíricamente la diversidad del mundo. $\mathrm{Y}$ en la medida en que su descripción se va perdiendo en ramificaciones confusas, alegoriza, de manera sutil, cómo hay que entender cualquier concepción de ese mundo. La forma refleja el contenido. La concepción literaria del libro sigue un programa científico que puede inferirse a partir de la propia forma. Lo que anuncia esa proliferación formal sería, visto de este modo, lo siguiente: Kosmos no

22 "falta [...] de una relación interna de las partes", "los elementos [...] distribuidos de manera casi desorganizada".

23 Todavía al final de su introducción al tomo quinto y último de Kosmos, Alexander von Humboldt añadió poco antes de morir- unas reflexiones sobre su propia lengua. De ese modo pretendía "nur das sorgsame Erstreben bezeichnen, durch Vervollkommnung der Form an die innige Verwandtschaft zwischen einzelnen Theilen wissenschaftlicher und rein litterarischer Werke $\mathrm{zu}$ erinnern; an eine Verwandtschaft und Behandlungsweise, die den ersteren keineswegs Gefahr bringt" ("designar el cuidadoso esfuerzo de recordar, por medio de la perfección de la forma, el íntimo parentesco entre las partes aisladas de obras científicas y de obras puramente literarias; el parentesco y el modo de tratar lo que en ningún modo constituye un peligro para lo primero") $(\mathrm{V}, 18)$.

24 "muchos elementos que, según criterios diferentes a los míos sobre lo que debe ser la composición de un libro sobre la naturaleza, pueden echarse de menos aquí".

25 Véase Fisch (1989); Daum (2002). 
es heterogéneo porque su autor no ha podido dominar el tema, sino que no es homogeneizable, ya que la naturaleza misma no acaba nunca de ser abarcada.

El filósofo Hans Blumenberg entendió la forma de Kosmos de un modo constructivo, como el intento de transmitir de manera artística la impresión que causa la naturaleza. (Blumenberg 1983: 281-299) ${ }^{26}$. Blumenberg se refiere a una frase programática de su autor: "Ein Buch von der Natur muß den Eindruck wie die Natur selbst hervorbringen" "27. Y en consonancia con una observación de Plinio el Joven sobre la obra del Viejo, dice que esto es "nec minus varium quam ipsa natura" ("no menos variado que la propia naturaleza") (II, 232). ¿Ha imitado Humboldt, en la variedad de su propia escritura, a la naturaleza de un modo artificial? ¿Podemos entender la composición de su libro, en su irregularidad, como un intento de simular las ramificaciones finas, rizomáticas de una planta? ¿Representa, en su extraña proliferación, la exuberancia de la vegetación tropical? Los últimos tres tomos, de hecho, tienden a una profusión que parece casi natural. Pero solo esos tres.

Una interpretación de la forma de una obra ha de abarcar también sus cambios. Quien observa los tomos por separado, puede comprobar una evolución en la propia superficie del texto. Como en muchos otros escritos de siete décadas de productiva actividad de publicación, Humboldt dio a Kosmos una forma propia, la cual no es presentada de manera regular de principio a fin, sino que tiene un desarrollo dinámico. También en la última obra de Humboldt, poéticamente, pasa algo singular. La pregunta acerca de la semántica de la forma puede ampliarse y precisarse. ¿Cómo cambia la forma de Kosmos? ¿Y qué significa ese cambio?

Además de la biografía, del tema, del fracaso o de la feliz mimesis de la naturaleza, hay de hecho otra explicación para la enigmática forma y su aún más enigmática génesis. La clave está en el capítulo que precede al efecto de proliferación natural. ¿Qué pasa, en realidad, antes de la dispersión? ¿De qué se trata al final del tomo dos? Aquí encontramos la justificación para la curiosa "composición" de Kosmos. Y esa justificación es política.

\section{Historia colonial del saber}

En el capítulo sobre la "Geschichte der physischen Weltanschauung" ("Historia de una visión del mundo física") con la que acaba el segundo volumen, el cual, a su vez, precede a la proliferación formal que se inicia en el tercero, Humboldt se cuestiona la "allmälige[] Entwickelung und Erweiterung des Begriffs vom Kosmos, als einem Naturganzen" (II, 135) ${ }^{28}$. En 385 páginas el autor narra la historia del saber de la geografía, en sentido amplio, como un conocimiento del mundo científico y antropológico. ¿Cómo ha concebido Humboldt la exploración del mundo? ¿Cómo ha descrito los acontecimientos que la han llevado adelante?

26 El filósofo estudia las imágenes de las que se sirve Humboldt para poner en escena la "legibilidad del mundo" en distintos registros metafóricos, especialmente en la pintura, el teatro, la anatomía, la literatura, el lenguaje, los viajes y los museos ("Cuadros", "Escena", "Fisionomía", "Libro", etc.).

27 "Un libro sobre la naturaleza ha de causar la impresión que la propia naturaleza causa" (Humboldt 1860: 23, en una carta enviada desde Berlín el 24 de octubre de 1834).

28 "paulatino desarrollo y ampliación del concepto de cosmos como un todo de la naturaleza". 
Para que los hombres tengan una idea de la Tierra, tendrían que experimentarla y ponerse en relación. Son varios los factores que Humboldt pide tener en cuenta: migración, comercio, guerras, actividad en el extranjero (comerciantes, traductores, mercenarios) y viajes de descubrimiento o exploración -como los suyos-.

Una significación central la tienen los desplazamientos imperiales y las campañas de colonización en las que confluyen varios factores (por ejemplo, los soldados que se quedan detrás, durante las campañas, como "Ansiedler" o "colonizadores" (II, 158)) y que Humboldt trata, por lo tanto, de un modo paradigmático. Estos son, a su juicio, los impulsos más duraderos en el proceso de la exploración del mundo. A partir de esos "momento principales", el autor divide la "Historia de una visión física del mundo" en capítulos individuales que están dedicados por separado a las naciones más expansionistas: los griegos, los macedonios, los ptolomeos, los romanos, los árabes, los españoles y los portugueses. En la medida en que esos pueblos extendieron su poderío, ampliaron el espacio del mundo conocido y estimularon su conocimiento. Colonialismo y ciencia mantienen una relación dialéctica ${ }^{29}$.

Y esa dialéctica no es positiva ni negativa, sino una relación sobria y ambivalente. La "wunderbare[] Zeit der Conquista" ("maravillosa época de la conquista"), afirma Humboldt, en provocativa oposición, fue un período "der Gewaltthätigkeit und des Entdeckungsschwindels" ("de ejercicio de la violencia y de frenesí descubridor") (II, 310). El autor de Kosmos parece vacilar entre el entusiasmo por los éxitos del saber y la comprensión de que éstos fueron siempre aparejados de saqueo y destrucción.

Como objetivo, Humboldt describe una general "Verbesserung des gesellschaftlichen Zustandes" ("mejoramiento de la situación social") (II, 339). Pero el aristócrata prusiano sabe bien el precio que pagan los hombres por ese "progreso". Son siempre comandos militares, exploraciones coloniales y campañas imperiales las que amplían el horizonte y abren nuevos campos para la investigación; es el poder que estimula el saber, es la guerra que pone en contacto a pueblos ajenos y los obliga a enfrentarse intelectualmente ${ }^{30}$.

Humboldt enfatiza lo forzoso e inconsciente de esa interacción: los movimientos de la expansión colonial difunden "erst Knechtschaft und dann", cuando ésta provoca su abolición, "unwillkührlich Freiheit über eine andere Erdhälfte" (II, 213). Incluso el Papa, cuando dividió el globo terráqueo con una "línea de de-

29 Observaciones en ese sentido ya las había hecho Humboldt no solo entre 1799 y 1804 en América, sino también en su segunda gran expedición en 1829 por Asia; véase "Die Dialektik des Kolonialismus" (Lubrich 2009: 857-859).

30 Humboldt escribía, en efecto, en una situación postcolonial. Las colonias españolas de América, a través de las cuales viajó durante cinco años, habían conseguido su independencia en la década de 1820, con la única excepción de Cuba. Y Humboldt también publicó en una situación revolucionaria. El segundo tomo de Kosmos apareció en 1846-1847, poco antes de la Revolución de 1848. Los planteamientos que se desarrollan aquí desde una perspectiva histórica y teórica, pueden ponerse en correspondencia con la práctica de su propia literatura postcolonial, en especial en relación con sus escritos sobre las colonias españolas en América en su fase de emancipación (1800-1830) y sobre el imperio ruso en su estado de opresión (1829). En su diario de viaje americano, ya Humboldt había condenado de forma categórica el colonialismo en cuanto tal: "l'idée de la Colonie même est une idée immorale" ("la idea misma de la colonia es una idea inmoral") (Humboldt 1982: 63). Pero la posición crítica de Humboldt queda clara también en sus publicaciones, por ejemplo en el Essai politique sur le royaume de la Nouvelle-Espagne: "Le Mexique est le pays de l'inégalité" ("México es el país de la desigualdad") (Humboldt 1811: I, 103). Wilke (2011) evalúa las contribuciones postcoloniales a los estudios humboldtianos.

31 "primero esclavitud y luego involuntariamente la libertad sobre el otro hemisferio". El subrayado es del autor. 
marcación" (II, 318) de esferas de poder entre España y Portugal, dio, "ohne es zu wissen" ("sin saberlo"), el motivo para que se realizaran mediciones más exactas y prestó "wesentliche Dienste" ("servicios esenciales") a la navegación y a la física (II, 321). A la inversa, el naturalista y explorador clásico Plinio, en su condición de "Statthalter in Spanien und Oberaufseher der Flotte" ("gobernador en España y de supervisor de la flota”) (II, 231), fue un actor del imperio.

El viajero va poniendo de relieve la ambivalencia de la racionalidad europea y la dialéctica del colonialismo ${ }^{32}$. El conocimiento es la otra cara de la expansión; la Ilustración, el acompañante del imperialismo; el intelectual, un colaborador del poder. Esa es la gran narración histórica en Kosmos, su grand récit. Humboldt recapitula la historia de la ciencia como historia de la violencia, cuyas etapas más importantes fueron la expansión de Grecia por la región del Mediterráneo, las campañas de Alejandro Magno en Asia, los grandes imperios helenos, el "dominio mundial romano", la entrada de los árabes y la colonización de América.

Así Alexander von Humboldt despliega una idea que Walter Benjamin llevará a una sentencia en sus tesis histórico-filosóficas: "Es ist niemals ein Dokument der Kultur, ohne zugleich ein solches der Barbarei zu sein"33. Investigación e invasión son dos aspectos que no se pueden separar en Humboldt -lo mismo que en el caso de Alejandro Magno y Colón-.

\section{La "expedición de Alexander"}

Un arquetipo de la relación entre conquista y ciencia lo constituyen las campañas de Alejandro Magno. Humboldt, por una parte, habla casi con ingenuidad de una "Bereicherung des Aristotelischen zoologischen Wissens durch die Heerzüge des Macedoniers" ("enriquecimiento del saber zoológico aristotélico a través de las campañas militares del macedonio") (II, 191). En otro pasaje, matizaría lo anterior: "Die macedonische Expedition", en su condición de campaña bélica, fue "wohlthätig für die Fortschritte der Erdkunde" ("beneficiosa para los progresos de la geografía") solo "im ganzen" ("en su conjunto") (II, 226).

El concepto de "expedición científica" que emplea para referirse a las campañas del discípulo del filósofo, Humboldt lo resalta incluso a través de la tipografía:

Die macedonische Expedition, welche einen großen und schönen Theil der Erde dem Einflusse eines einzigen und dazu eines so hochgebildeten Volkes eröffnete, kann demnach im eigentlichsten Sinne des Worts als eine wissenschaftliche Expedition betrachtet werden: ja als die erste, in der ein Eroberer sich mit Gelehrten aus allen Fächern des Wissens, mit Naturforschern, Landmessern, Geschichtsschreibern, Philosophen und Künstlern umgeben hatte (II, 192-193) ${ }^{34}$.

32 Para una lectura dialéctica del viaje de James Cook y Georg Forster véase Berman (1998). Sobre la dialéctica de la historia colonial brasileña véase Bosi (2009).

33 "No hay documento de civilización que no sea al mismo tiempo documento de la barbarie" (Benjamin 1991: I, 696).

34 "La expedición de los macedonios, que abrió una amplia y hermosa parte de la Tierra a los influjos de un pueblo único y, además, sumamente instruido, puede ser vista, en el sentido más genuino de la palabra, como 
Cuando se combinan las palabras "expedición" y "Alejandro", se insinúa un doble sentido de carácter siniestro. Porque si bien por un lado esas palabras designan la campaña bélica del rey, pueden relacionarse igualmente, por otro lado, con los viajes de exploración e investigación del autor que compartía nombre de pila con el primero: "Alexanders Expedition" (II, 195-196)

En sentido figurado, no solo la actividad viajera de Humboldt es una expedición literaria; también lo es su Kosmos. Ambas sirven para explorar el mundo. Kosmos conduce al lector a través de un viaje por el Universo, un viaje que comienza por las nebulosas más remotas del espacio sideral y va midiendo en su camino hacia las rocas y musgos, los animales y los hombres en la Tierra, los espacios más disímiles del saber.

El hecho de que Alexander von Humboldt califique pocas veces, a lo largo del segundo tomo, al otro Alexander den Großen, con el epíteto que lo distingue de él (lo hace solo dos veces en más de treinta pasajes del texto principal), es un indicio de que el autor de Kosmos no deseaba evitar la asociación, sino más bien sugerirla. En el caso de otras personalidades históricas emplea el mismo epíteto con suma regularidad: son los casos de Constantino, Basilio, Teodosio, Alberto y Federico.

Cuando el autor de Ansichten der Natur y de Ansichten der Kordilleren (Vues des Cordillères) habla de un modo muy parecido de "Alexanders [...] Ansichten" (II, 201), se produce de nuevo una superposición de ambas figuras, el conquistador del mundo y el hombre que lo describe, sobre todo en el pasaje citado en el que la palabra Ansichten (puntos de vista) se refiere a los planes del rey macedonio para los exóticos territorios explorados y explotados.

Ambas dimensiones de la exploración y la explotación del mundo, la dimensión colonial y la científica, coinciden también, como en Alejandro Magno, en la figura y en el viaje de Cristóbal Colón, de quien Humboldt se consideró un seguidor. Las exploraciones marítimas de los siglos XV y XVI superaron con creces, en ambos sentidos, los acontecimientos precedentes en la Antigüedad:

Wie in Alexanders Heerzügen, aber mit noch überwältigenderer Macht, drängte sich jetzt die Welt der Objecte, in den Einzelformen des Wahrnehmbaren wie in dem Zusammenwirken lebendiger Kräfte, dem combinirenden Geiste auf $\left(\right.$ II, 267) ${ }^{36}$.

La "expedición" de Colón fue, como destaca Humboldt, una especie de experimento: había tenido "den Charakter der Ausführung eines nach wissenschaftlichen Combinationen entworfenen Planes" ("todo el carácter de realización de un plan concebido a partir de combinaciones científicas") (II, 277). El hecho de que las expediciones equivalgan a "Heerzüge[n]" ("campañas militares") (II, 323) y que

una 'expedición científica': la primera, sí, en la que un conquistador se rodeó de eruditos en todas las disciplinas del saber: naturalistas, agrimensores, historiadores, filósofos y artistas".

35 El término "expedición" se refiere - por un lado- a las campañas militares ("Expedition des Cortez" (II, 309)) o incluso a la piratería ("die [...] auf Menschenraub und Plünderung gerichteten Expeditionen" (II, 173)) y por otro lado- aluden a los viajes de investigación ("Halley [...] in seinen magnetischen Expeditionen" (II, 380)).

36 "Como en las campañas militares de Alejandro, pero con una fuerza aun más imponente, el mundo de los objetos se imponía ahora en las formas individuales de lo perceptible, así como en la interacción de las fuerzas vivas, a las capacidades combinatorias del espíritu". El subrayado es del autor. 
éstas, a su vez, estén relacionadas con experimentos, es algo que cuestiona la propia actuación de Humboldt. Porque si una campaña militar es también una empresa científica, cualquier viaje de exploración de la naturaleza es a la vez un proyecto colonial.

Como ha demostrado Edward Said a partir del ejemplo de la "expedición" de Napoleón en Egipto, la cual conforma el inicio de su historia sobre el Orientalismo moderno (Said 1994: 73-92), la conquista de carácter militar y el estudio científico iban de la mano ya desde la época de Humboldt. También la campaña de Francia de 1798, que Humboldt no aborda en su historia, iba acompañada de una caravana de expertos, de "orientalistas", cuyos conocimientos lingüísticos, culturales y geográficos fueron de gran ayuda para el ejército. El propio Humboldt estuvo a punto de verse involucrado en esta empresa de doble propósito. Porque precisamente ella se produce, biográficamente, al comienzo de su propio proyecto, proporcionándole a éste su rumbo geográfico y discursivo en la medida en que canceló sus planes de un viaje por el Oriente al tiempo que estimulaba cierta orientalización en sus descripciones de América ${ }^{37}$.

Los comentarios de Humboldt sobre la expedición de Alejandro Magno y sobre el experimento de Cristóbal Colón, que unen conquista y ciencia, han de entenderse como una velada crítica a Napoleón: pero también como una autocrítica indirecta. Y ambas constituyen un ejemplo del método que caracteriza a Kosmos: un método sistemático en el que la historia colonial y la historia científica se solapan a través de una serie de vocablos de doble sentido.

\section{Homonimia}

La dialéctica entre colonialismo y ciencia no solo es en Humboldt un tema, sino que esa dialéctica atraviesa toda su retórica. Un elemento central son las palabras homónimas que designan tanto un proceso colonial como uno científico, estableciendo un contacto entre la violencia y el conocimiento. Esto puede ilustrarse, además de con la palabra Expedition, con otros ejemplos: Entdeckung, Einfall, Eroberung.

El término Entdeckung (descubrimiento) puede significar lo mismo la apertura territorial de un espacio por poblar y conquistar ("Entdeckung von Amerika" (II, 164)) que la investigación intelectual de procesos naturales ("Arago's Entdeckung der farbigen Polarisation" (II, 136)).

La palabra Einfall (incursión, idea, ocurrencia) se refiere primeramente a una intuición de carácter científico ("de[r] Einfall [...], die Aërolithen kämen aus dem Monde", "la idea de que los aerolitos venían de la Luna" (I, 401)). Sin embargo, más adelante, la palabra aparece con otro significado, destacada en un titular, con la acepción de invasión bélica: "Einfall der Araber", "Incursión de los árabes" (II, 237).

El substantivo Eroberung (conquista) queda duplicado por Humboldt mediante el atributo "zwiefach" (doble, dos veces, ambivalente), con lo cual se destaca de

37 Véase "“Egipcios por doquier”" (Lubrich 2003: 75-101); “"A la manera de los beduinos"” (Lubrich 2003: 1129). 
manera discreta la ambivalencia del propio imperialismo: "diese[] zwiefachen Eroberungen in der physischen und in der intellectuellen Welt" (II, 299) ${ }^{38}$. Los españoles conquistaron el Nuevo Mundo para su imperio y para la geografía.

Para ilustrar los procesos intelectuales Humboldt emplea con regularidad algunas expresiones militares, como por ejemplo Vordringen (avanzar, penetrar, ganar terreno, adentrarse): "penetrar" en el espacio sideral con el telescopio como si fuera necesario colonizarlo (II, 136; II, 258). De un modo similar, describe la capacidad colonizadora de las lenguas y las ideas: por ejemplo, esa "Gewalt" ("fuerza") (II, 141-142) que ejerció la lengua griega sobre otros pueblos. De forma enfática se habla del "Herrschaft der Ideen" (“dominio de las ideas") (II, 206). Y también la labor de los científicos es revestida por Humboldt, conscientemente, de conceptos coloniales. Sus esfuerzos, entre los que se cuenta su propio proyecto, tienen como objetivo el de "durch die Macht der Intelligenz den weiten Erdkreis zu erobern" $(\mathrm{I}, 4)^{39}$. Describir el mundo significa dominarlo.

El concepto de Weltherrschaft, "dominio mundial", no solo se emplea para designar la cambiante hegemonía de varias naciones (los romanos, los persas, los chinos, los mongoles y los árabes), sino que, mediante palabras compuestas, se sitúa en analogía con otros que crean a su modo referencias al mundo de tipo cognitivo, económico, político o colonial. El propio subtítulo de la obra, Ensayo de una descripción física del mundo (Entwurf einer physischen Weltbeschreibung), y el título del capítulo principal, "Geschichte der physischen Weltanschauung" ("Historia de una visión física del mundo"), habían dado perfil a esa forma ${ }^{40}$. Sobre todo en este capítulo numerosos términos análogos se contaminan unos a otros: "Welthändel" (conflictos internacionales), "Welthandel" (comercio internacional), "Weltverkehr" (tráfico), "Weltveränderung" (cambio), "Weltgestaltung" (organización), "Weltstürmer" (conquistador), "Weltreich" (imperio), "Weltordnung" (orden), "Weltzusammenhang" (contexto), "Weltgeschichte" (historia), "Weltkarte" (mapa), "Weltumschiffung" o "Weltumsegelung" (circunnavegación), "Weltmeer" (océano), "Weltkunde" (geografía), "Weltansicht" (visión), "Weltanschauung" (conocimiento), "Weltbewußtsein" (conciencia), "Weltbeschreibung" (descripción) ${ }^{41}$. Los términos que designan el propio proyecto de Humboldt, ya sea en el subtítulo de Kosmos, "Weltbeschreibung", o en el título de su capítulo dedicado a la historia, "Weltanschauung", corresponden anafórica y fonéticamente a otros que describen el colonialismo.

\section{Metáforas del colonialismo}

Reveladora resulta no únicamente la manera en que se entiende a través de las ideas y los conceptos la exploración y explotación del mundo o cómo éstas, con la ayuda de palabras homónimas, quedan puestas de manifiesto en toda su ambivalencia, sino también las imágenes con las que se las representa. Para abarcar la investigación como efecto o premisa de expansión política, Humboldt emplea tres metá-

\footnotetext{
“estas dobles conquistas en el mundo físico y en el mundo intelectual". El subrayado es del autor. "conquistar mediante la fuerza de la inteligencia el amplio globo terráqueo". El subrayado es del autor. Los subrayados por separación de letras han sido añadidos.

Véase Ette (2002).
} 
foras fundamentales que sirven como modelos de lectura y de comprensión: la luz, el agua y las plantas ${ }^{42}$.

1. Luz: Las civilizaciones aparecen como "Lichtpunkte des Wissens" ("puntos de luz del saber") (II, 248), como "leuchtende Puncte, Centra der Cultur, die gegeneinander strahlen" ("puntos luminosos, centros de la cultura que se iluminan unos a otros") (II, 146) y en cada caso, en una "Sphäre" ("esfera") específica (II, 316), difunden a su alrededor la claridad. La antítesis, la cual confirma lo contrario, es la oscuridad alegórica ("in den dunkeln Zeiten des Mittelalters", "en los tiempos oscuros de la Edad Media" (II, 140), "wieder verdunkelt", "otra vez oscurecido" (II, 227)).

2. Agua: Desde distintas "Quellen" ("fuentes") (II, 239), o incluso desde un singular "Urquell" ("fuente primigenia") (II, 146) se vierten las civilizaciones como "Ströme" ("corrientes") (II, 148) o como "Völkerfluthen" ("inundaciones de pueblos") (II, 220) sobre otras aguas (II, 149), y de ese modo han ejercido su "Einfluß" ("influencia") (II, 56).

3. Plantas: De "Keime[n]" ("semillas") depositadas en un "fruchtbaren Boden" ("suelo fértil") (II, 200) surgen las plantas de las civilizaciones que llegan a su "Blüthe" ("florecen") (II, 201), dan "Früchte" ("frutos") (II, 268) y producen nuevas "befruchtende Keime" ("semillas fecundadoras") (II, 268), las cuales "ausgestreut [werden]" (se "diseminan") (II, 268) y "[sich] fort[ ]pflanz[en]" (se "procrean") (II, 170) y arriban a otros lugares, en los que, "[ ]wurzel[n]" ("echan raíces") (II, 179) y vuelven a "erblüh[en]" ("florecer") (II, 178). "[D]urch die Verpflanzung einheimischer Cultur [werden] überall neue Keime [...] hervorgerufen" ("Mediante el trasplante de cultivos autóctonos se producen [...] nuevas semillas") (II, 178), por ejemplo, "Saamen abendländischer Cultur, in Persien [...] ausgestreuet" ("semillas de cultivos occidentales diseminados [...] en Persia") (II, 248). En ese sentido "[ist] ursprünglich gewurzelt" ("echó raíces originalmente"), por ejemplo, "unsere jetzige wissenschaftliche Cultur" ("nuestra cultura científica actual") (II, 149) en las civilizaciones del Mediterráneo, que se habrían "auf europäischem Boden fortgepflanzt" ("trasplantado a suelo europeo") aun teniendo su origen en "Keim[en]" ("semillas") orientales y africanas (II, 149, véase también II, 212).

Este repertorio metafórico tomado de la botánica se concentra, de acuerdo con la etimología del término colonia (colere), en el concepto de las "Pflanzstädte" o ciudades plantadas (II, 178), empleado como sinónimo de colonias de ultramar: el "Colonial-System" (II, 178) es "System der Anlegung von Pflanzstädten" ("un sistema de implantación de ciudades") (II, 177). Humboldt abunda en este tipo de metáforas. La "ionische Leben" ("vida iónica"), por ejemplo, "[hat] überall, wo es in den Pflanzstädten verbreitet war, die wohlthätigen Keime fortschreitender Bildung ausgestreut" ("diseminó, en todas partes donde se propagó en las ciudades implantadas, las más beneficiosas semillas de una educación progresista") (II, 173). También las personas destinadas a poblar territorios eran "verpflanzt[ ]"

42 Véase "Stufen, Keime, Licht” (Lubrich 2009: 167-190). 
("trasplantadas") (II, 273). Sin embargo, el término "Pflanzstadt" hay que entenderlo tanto en un sentido pasivo como activo, ya que esas nuevas colonias "plantadas" también "plantaron", por su parte, "otras ciudades", colonias de segundo grado ("andere Pflanzstädte gründeten") (II, 178). Tales imágenes de vida vegetal sugieren la idea de que se trata de un proceso natural -lo que corresponde a una estrategia ideológica del discurso colonial (Pratt 1992)-.

La luz, el agua y las plantas constituyen conceptos metafóricos, no sólo en Humboldt, de la expansión e interacción de las culturas. Poseen en cada caso una lógica espacial y de movimiento: una concéntrica, una lineal y una rizomática. Ello es, en primer lugar, la idea de una expansión circular como la que caracteriza a la expansión de la luz y que puede extrapolarse a las ideas: "Gesichtskreis" (campo visual) (II, 168; II, 174), "Ideenkreis" (esfera de ideas) (II, 153), "Kreis des Wissens" (circuito del saber) (II, 162) ${ }^{43}$. En cierto modo, la luz de las culturas y las civilizaciones se mueve, y lo hace también por medio de contactos, migraciones y guerras, como "Lichtstreifen" (II, 268), se mueve en diferentes direcciones, pero no con exactitud geométrica, sino por caminos indeterminados: "Das Licht, welches in dem von tatarischen Völkern bewohnten Asien angezündet war, verbreitete sich [...] weiter in Westen" ("La luz encendida en Asia por los pueblos tártaros que la habitaban, se difundió [...] más hacia el oeste”) (II, 261). La concepción ilustrada de la difusión de la luz, que podría pensarse en términos eurocéntricos, mientras que Humboldt, por su parte, cree entenderla en un sentido policéntrico, como "von mehreren Punkten ausgehende[ ] Verbreitungsstrahlen" "des Menschengeschlechts" "rayos difusores" del "género humano" que "parten desde varios puntos") (II, 143), queda cubierta por otras dos ideas en emulación, las cuales están relacionadas con la experiencia de su viaje y su práctica como explorador: el estudio de las aguas y la geografía de las plantas.

También para el concepto de las corrientes y los flujos Humboldt enfatiza que este no puede entenderse en un sentido lineal y unidireccional, sino plural y difusivo: por ejemplo, cuando muestra "was dem großen Strome griechischer und römischer Cultur auf mannigfaltigen [...] Wanderungswegen aus dem Nilthale und aus Phönicien, vom Euphrat her oder aus Indien zugeführt worden ist" (II, 213) ${ }^{44}$. "Man kann die Hauptströme bezeichnen [...]; aber bei der Vielfachheit dieser Ströme ist nicht ein einiger Urquell zu nennen" (II, 146) ${ }^{45}$. La consecuencia es la confluencia. "Europa und Asien [sind] durch flache Steppenländer wie in einander verflossen" ("a través de las llanas regiones de la estepa han confluido una en la otra") (II, 171). Las corrientes marinas que el propio viajero pudo observar durante su travesía rumbo a América, fueron recogidas y estudiadas por él en el primer tomo de su Relation historique, y no solo desde un punto de vista científico ${ }^{46}$, sino

43 Al motivo del círculo, como expone Humboldt, hay que circunscribirle etimológicamente el modelo de la enkyklopaideía a la que se remite Plinio en su Historia naturalis ("Encyclopädie der Natur und Kunst" (II, 230), “[d]as encyclopädische Wissen" (II, 206)).

44 "lo que se le suministró al gran flujo de cultura griega y romana a través de diversas [...] vías migratorias que partieron del valle del Nilo y de los fenicios, del Éufrates o de la India".

45 "Es posible designar esas corrientes principales [...]; pero vista la variedad de esas corrientes no podemos mencionar una única fuente original".

46 "Deux cadavres, dont les traits annonçoient une race d'hommes inconnue, furent jetés, vers la fin du quinzième siècle, sur les côtes des îles Açores" ("Dos cadáveres cuyos rasgos anunciaban una raza de hombres 
también simbólico, en la medida en que describía la circulación del Atlántico como una circulación intercontinental de vegetación, barcos vacíos o cadáveres de razas exóticas, algo que vinculaba para bien y para mal al 'Viejo' con el 'Nuevo Mundo ${ }^{47}$.

La "geografía de las plantas" que Humboldt introduce al comienzo del capítulo sobre la "Historia de una visión física del mundo" (II, 136) ya la había introducido también en la publicación, cronológicamente anterior, de su obra sobre el viaje por América, el Essai sur la géographie des plantes (1807), presentado como una teoría de las migraciones históricas que no solo son análogas a las migraciones humanas, sino que están en una relación directa con ellas.

En general, Humboldt parece dejarse guiar por dos suposiciones básicas: el saber, aunque no lo haga de forma pareja, sí que aumenta con el tiempo. Hay un progreso. Y el punto de partida de ese progreso es la vieja Europa, cuya perspectiva él adopta desde el comienzo. A Humboldt le sirve "[d]as Mittelmeer als Ausgangspunkt", el "Mediterráneo como punto de partida" (II, 151), como "Ausgangspunkt [...] der Colonisirung", "punto de partida [...] de la colonización" (II, 151), y le sirve por razones pragmáticas y heurísticas. "Wir wählen" ("Elegimos") este principio, escribe Humboldt, porque cree "von einem eingeschränkten Erdraume ausgehen zu müssen" ("tener que partir de un espacio limitado de la Tierra") (II, 146); porque "am geeignetsten" ("lo más apropiado") es "von einer Völkergruppe [...] auszugehen" ("partir [...] de un grupo de pueblos") (II, 149).

Pero el modelo de Humboldt no es greco-céntrico. No empieza con los griegos, sino con sus antecesores no europeos: los egipcios y los fenicios (así como otros pueblos semitas), y a través de ellos llega más tarde a los etruscos. Existen, en cada caso, influencias anteriores: "Fremde Elemente wurden aufgenommen" ("se adoptaron elementos foráneos") (II, 178). El Kosmos de Humboldt ni siquiera es eurocéntrico. El autor ilustra la participación de pueblos no europeos en el "progreso" y en la expansión imperial: los indios, los chinos, y especialmente los árabes, a los que dedica un capítulo entero de su "Historia": sobre el "Einfluß der arabischen Civilisation" ("influencia de la civilización árabe") (II, 296). Los conceptos de civilización y barbarie quedan de ese modo nuevamente distribuidos: "Die Araber, ein semitischer Urstamm, verscheuchen theilweise die Barbarei, welche das von Völkerstürmen erschütterte Europa bereits seit zwei Jahrhunderten bedeckt hat" $\left(\right.$ II, 239) ${ }^{48}$. La oposición entre 'propio' y 'ajeno' queda de ese modo reinvertida. La "Historia de una visión física del mundo", distinta al difusionismo, tiende a la "hibridación': a la "gegenseitige Befruchtung" ("fecundación mutua") (II, 297), a la "Vermischung" ("mestizaje") (II, 183) y a la "Verschmelzung" ("fusión") (II, 219). Tales principios de disolución de un concepto homogéneo, cerrado y esencialista de la cultura anticipan una visión central de los estudios culturales postcoloniales (Bhabha 1994).

También en sus observaciones científicas sobre la naturaleza la obra Kosmos se ve atravesada por una teoría de la identidad y la diferencia que ya no tiene una

desconocidos, fueron arrojados hacia finales del siglo quince a las costas de las islas Azores") (Humboldt 1814/1819/1825: I, 63-72, aquí 71).

47 Véase Honold (2013).

48 "Los árabes, una tribu semita originaria, espantaron en parte la barbarie que había cubierto a una Europa sacudida por las agresiones de los pueblos desde hacía dos siglos". 
organización binaria. La ciencia empírica desemboca en todas partes en los mismos resultados: tras la variedad superficial se oculta un elemento común fundamental. De modo que la corteza terrestre es en cada lugar la misma, aun cuando las plantas y los animales que la habiten sean diferentes. En la naturaleza, y en los asuntos de los hombres, lo que importa es encontrar "Einheit in der Vielheit" (la "unidad en la variedad") (I, 5). En el reino de Prusia había muchas cosas que incitaban el disgusto de Humboldt. "Die Natur aber ist das Reich der Freiheit" ("Pero la naturaleza es el reino de la libertad”) (I, 4). Kosmos no es únicamente un libro científico.

\section{Poética postcolonial}

¿Cuál es, entonces, la "composición” de Kosmos y cómo hemos de entender su desarrollo tan singular si lo remitimos al capítulo que lo precede? Si, en efecto, tuviéramos que ver la explicación para esta confusa división en el ensayo sobre la "Historia de una visión física del mundo", se trataría entonces de la confrontación con la dialéctica del colonialismo y la ciencia. La crítica al colonialismo como crítica de la ciencia que Humboldt expone en su teoría sobre la exploración (y explotación) del mundo, habría generado una reacción literaria.

El Kosmos de Humboldt empezó como un proyecto imperial, el de un intento por abarcar el mundo. Y, en correspondencia, se inicia con una forma adecuada que estaba estructurada de una manera jerárquica convencional (tomo 1). Pero luego el autor desarrolla una reflexión crítica sobre la relación entre conocimiento del mundo y conquista del mismo, reflexión que cuestiona esa forma (tomo 2). Y de ello extrae Humboldt las conclusiones artísticas en la medida en que libera la forma poética (tomos 3-5). Un proyecto megalómano se descontrola. La forma de Kosmos se vuelve anti-imperial.

En otras palabras: la "Historia de una visión física del mundo", de Humboldt, tiene consecuencias tanto políticas como literarias. La forma en la que el autor representa su propio proyecto de una exploración del mundo deja de clasificar de manera taxonómica y clara, y en su lugar se vuelve híbrida, heterogénea. Ya no está organizada desde una perspectiva centralizadora, sino que se despliega de un modo descentralizado. Teniendo en cuenta su propia crítica al colonialismo, el autor de Kosmos ya no podía escribir el mismo libro.

La proliferación de la escritura ha de entenderse, pues, como una reacción al colonialismo cuya historia crítica la precede en Kosmos: como una poética postcolonial en un doble sentido. Para esa "visión física del mundo" es válido lo que había dicho el inspector de minas con mirada de geólogo sobre las estratificaciones de la tierra: "Ihre Form ist ihre Geschichte" (I, 64). La "forma" del libro sigue la "historia" de lo que trata: la historia del saber como historia de la violencia".

49 Alexander von Humboldt no solo se plantea la cuestión del papel de la ciencia en el proceso colonial, sino también la del papel de las artes. Dado que en el capítulo que antecede a la "Historia de una visión física del mundo" él muestra la relación de los estudios sobre la naturaleza con la literatura, la pintura y la jardinería, y las presenta, por una parte, como "medios de estímulo" y como formas de expresión, por la otra, ese estudio puede leerse como un modelo de la relación triangular existente entre el imperialismo, la ciencia y la cultura, una relación que se debate más tarde en los estudios postcoloniales (desde Edward Said hasta Homi Bhabha). 
A primera vista Humboldt parece copiar en su libro la insólita proliferación de los imperios que ha descrito en su capítulo histórico y reflejarla en la manera en que prolifera su texto. Al tomarse en serio la etimología botánica, su estudio del colonialismo desarrolla una forma mimética de representación, como una nueva posibilidad crítica y no homogénea de entender las culturas. Dado que esa proliferación textual no atañe concretamente al capítulo sobre el colonialismo, sino a aquella parte de la obra que le sigue a éste, la intención no puede haber sido presentar esa nueva conclusión obtenida solo en ese determinado objeto. Sus consecuencias pasan a influir más bien en su propio proyecto: a la propia relación con el mundo y a la propia escritura.

Ese cambio de las estrategias de escritura puede haberse beneficiado de la actitud experimental con la que Humboldt había emprendido su proyecto. El 24 de octubre de 1834 le escribía a su amigo Varnhagen von Ense una frase en la que expresa someramente su idea para el libro Kosmos:

Ich habe den tollen Einfall, die ganze materielle Welt, alles, was wir heute von den Erscheinungen der Himmelsräume und des Erdenlebens, von den Nebelsternen bis zur Geographie der Moose auf den Granitfelsen wissen, alles in $e i$ nem Werk darzustellen, und in einem Werk, das zugleich in lebendiger Sprache anregt und das Gemüt ergötzt ${ }^{50}$.

El adjetivo "toll" ("disparatado") es preciso entenderlo aquí tanto de manera polisémica como irónica ${ }^{51}$. Su, en efecto, "disparatada" ocurrencia ("Einfall", con la cual anticipa la misma palabra que usará para hablar del "Einfall der Araber", de la "incursión de los árabes"), Humboldt la presenta de tal modo como para que no solo resalte la grandeza, sino también la locura de la empresa. Cada vez que alude, en repetidas ocasiones, al carácter planificado de su escritura, para lo cual usa términos como "composición", llegamos a la conclusión de que Humboldt concibió su Kosmos, conscientemente, de un modo anti-convencional. Pero tal diseño podrá adoptar luego una dinámica propia que producirá excesos insospechados ${ }^{52}$.

La composición caprichosa del Kosmos, esa curiosa dinámica de la forma en su dimensión política, ha de entenderse desde la perspectiva de los estudios postcoloniales que, en general, ponen más énfasis en criticar la ideología que en apreciar la estética de su material, por no mencionar sus contradicciones y modificaciones ${ }^{53}$. Sin embargo, Humboldt no es solo el 'clásico' alemán que afrontó de manera más intensa la cuestión del colonialismo, lo mismo en su condición de viajero que de historiador. Él es, al mismo tiempo, el autor en cuyos escritos esa confrontación es

50 "Tengo la disparatada idea de plasmar en una sola obra todo el universo material, todo lo que hoy en día sabemos de los fenómenos de los espacios celestes y de la vida terrestre, desde las nebulosas estelares hasta la geografía de los musgos en las rocas de granito, de plasmar todo en una obra, con un estilo vivo que causará deleite y cautivará la sensibilidad" (Humboldt 1860: 20).

51 En un sentido negativo de "loco", "disparatado", pero también en el sentido positivo de "alegre", "admirable", "grande y bello" (Grimm / Grimm 1935: 631-636).

52 Cuando las imágenes verbales con las que Humboldt ilustra su criterio acerca del colonialismo se superponen, crean incongruencias que no parecen controladas en su totalidad. Hay, por ejemplo, "puntos de luz" que "resplandecen" y difunden el "brillo", pero también "contienen semillas de puntos de vistas generales sobre el cosmos" (II, 316); o una "oleada de pueblos" que se ha "implantado" (II, 220-221).

53 Lecturas más complejas de autores germanófonos del siglo XIX (Kleist, Hoffmann, Eichendorff, Stifter, Storm, Keller, Raabe, Fontane) presenta, por ejemplo, Dunker (2008). 
presentada también de manera artística. Ello encuentra su expresión en formas siempre nuevas, cuya transformación refleja también el proceso del conocimiento en su autor ${ }^{54}$. Alexander von Humboldt puso en escena al mundo entero como un espacio colonial. E intentó explorar ese espacio en su poética postcolonial.

\section{Referencias bibliográficas}

Agassiz, L., «〈Alexander von Humboldt - Eulogy», by Prof. Agassiz, before the American Academy of Arts and Sciences, delivered on the $24^{\text {th }}$ of May», American Journal of Science and Arts (serie segunda) 28 (1859), 96-107.

Benjamin, W., «Über den Begriff der Geschichte», en: Tiedemann, R. y Schweppenhäuser, H. (eds.), con Adorno, T. W. y Scholem, G., Gesammelte Schriften. 7 vols., Frankfurt: Suhrkamp 1991, t. I (ensayos), 691-704.

Berman, R., Enlightenment or Empire. Colonial Discourse in German Culture. Lincoln: University of Nebraska Press 1998.

Bhabha, H., The Location of Culture. New York: Routledge 1994.

Blumenberg, H., «Ein Buch von der Natur wie ein Buch der Natur», en: Die Lesbarkeit der Welt [1981]. Frankfurt: Suhrkamp 1983, 281-299.

Böhme, H., «Ästhetische Wissenschaft. Aporien der Forschung im Werk Alexander von Humboldts», en: Ette, O., Hermanns, U., Scherer, B. M. y Suckow, C. (eds.), Alexander von Humboldt - Aufbruch in die Moderne. Berlín: Akademie 2001, 17-32.

Bosi, A., Dialética da colonização. São Paulo: Companhia das Letras 2009.

Büchner, G., «Dantons Tod», en: Knapp, G. P. y Wender, H. (eds.), Gesammelte Werke. Múnich: Goldmann 1988, 7-96.

Daum, A. W., Wissenschaftspopularisierung im 19. Jahrhundert. Bürgerliche Kultur, naturwissenschaftliche Bildung und die deutsche Öffentlichkeit, 1848-1914. Múnich: Oldenbourg 2002.

Dunker, A., Kontrapunktische Lektüren. Koloniale Strukturen in der deutschsprachigen Literatur des 19. Jahrhunderts. Múnich: Fink 2008.

Ette, O., Weltbewußtsein. Alexander von Humboldt und das unvollendete Projekt einer anderen Moderne. Weilerswist: Velbrück 2002.

Ette, O. y Lubrich O., «Die andere Reise durch das Universum», en: Ette, O. y Lubrich, O. (eds.), Humboldt, A. v., Kosmos. Entwurf einer physischen Weltbeschreibung. Frankfurt: Die Andere Bibliothek 2004/2014, 905-920.

Ette, O. y Lubrich, O., «Zu diesem Kartenwerk», en: Ette, O. y Lubrich, O. (eds.), Berghaus, H., Physikalischer Atlas. Frankfurt: Die Andere Bibliothek 2004/2014, IX-XIII.

Fisch, S., «Forschungsreisen im 19. Jahrhundert», en: Brenner, P. J. (ed.), Der Reisebericht. Die Entwicklung einer Gattung in der deutschen Literatur. Frankfurt: Suhrkamp 1989, 383-405.

Grimm, J. y Grimm, W., Deutsches Wörterbuch. T. 11, sección primera, parte I [T-Treftig], Leipzig: S. Hirze 1935.

Honold, A., «Strömungslehre bei Humboldt und Hölderlin», en: Lubrich, O. y Knoop, C. (eds.), Cumaná 1799. Alexander von Humboldt's Travels between Europe and the Americas. Bielefeld: Aisthesis 2013, 7-28.

54 Sobre el potencial de Humboldt para los estudios postcoloniales, véase Lubrich (2005); Lubrich (2010). 
Humboldt, A. v., Essai sur la géographie des plantes. París: Schoell/Tübingen: J. G. Cotta 1807.

Humboldt, A. v., Essai politique sur le royaume de la Nouvelle-Espagne. 2 vols., París: F. Schoell 1811.

Humboldt, A. v., Relation historique du Voyage aux régions équinoxiales du Nouveau Continent. 3 vols., París: F. Schoell 1814; N. Maze 1819; J. Smith et Gide fils 1825 (tomos 1-3 de Voyage).

Humboldt, A. v., Kosmos. Entwurf einer physischen Weltbeschreibung. 5 vols., Stuttgart/Tübingen: Cotta 1845-1862.

Humboldt, A. v., Cosmos ó ensayo de una descripción física del mundo. Trad. de Díaz Quintero, F., 2 vols. Madrid: Ramón Rodríguez de Rivera, 1851-1852.

Humboldt, A. v., Briefe von Alexander von Humboldt an Varnhagen von Ense aus den Jahren 1827 bis 1858. Leipzig: Brockhaus 1860.

Humboldt, A. v., Cosmos. Ensayo de una descripción física del mundo. Giner, B. y de Fuentes, J. (trads.), 4 vols. (Obras de Alejandro de Humboldt). Madrid: Gaspar y Roig, 1874-1875.

Humboldt, A. v., Lateinamerika am Vorabend der Unabhängigkeitsrevolution. Trad. y ed. de Faak, M., Berlín/RDA: Akademie 1982.

Humboldt, A. v., Kosmos. Entwurf einer physischen Weltbeschreibung. Ette, O. y Lubrich, O. (eds.). Frankfurt: Die Andere Bibliothek 2004.

Humboldt, A. v., Cosmos. Ensayo de una descripción física del mundo. Trad. de Giner, B., de Fuentes, J. y Norak (tomo 5). Ed. de Rebok, S. Madrid: Los libros de la Catarata/CSIC 2011.

Lubrich, O., «〈Egipcios por doquier〉. Alejandro de Humboldt y su visión 〈orientalista〉 de América», Revista de Occidente 260 (2003), 75-101.

Lubrich, O., «〈A la manera de los beduinos〉. Alejandro de Humboldt 〈orientaliza〉 a América», Casa de las Américas 232 (2003), 11-29.

Lubrich, O., «Welche Rolle spielt der literarische Text im postkolonialen Diskurs?», Archiv für das Studium der neueren Sprachen und Literaturen 157 [242] (2005), 16-39.

Lubrich, O., «Spaltenkunde», en: Mittelmeier, M. (ed.), Ungeschriebene Werke. Múnich: Luchterhand 2006, 39-54.

Lubrich, O., «Die Dialektik des Kolonialismus», en: Die andere Reise des Alexander von Humboldt, en: Humboldt, A. v., Zentral-Asien. Frankfurt: S. Fischer 2009, 845-885.

Lubrich, O., «Stufen, Keime, Licht. Alexander von Humboldt als Ethnograph und Anthropologe», en: Humboldt, A. v., Ueber die Urvölker von Amerika. Hannover: Wehrhahn 2009, 167-190.

Lubrich, O., «Postcolonial Studies», en: Schmid, U. (ed.), Literaturtheorien des 20. Jahrhunderts. Stuttgart: Reclam 2010, 351-376.

Lubrich, O., «Das Wuchern der Imperien. Alexander von Humboldts Kosmos als postkoloniale Theorie», en: Dürbeck, G. y Dunker, A. (eds.), Postkoloniale Germanistik. Bielefeld: Aisthesis 2014, 193-222.

Pratt, M. L., "Alexander von Humboldt and the reinvention of América», en: Imperial Eyes. Travel Writing and Transculturation. Londres / Nueva York: Routledge 1992, 111-143.

Sachs, A., The Humboldt Current. Nineteenth Century Exploration and the Roots of American Environmentalism. Nueva York: Viking 2006.

Said, E. W., Orientalism [1978]. Nueva York: Vintage 1994. 
Whitman, W., «Kosmos», en: Leaves of Grass. Boston: Thayer \& Eldridge 1860-1861, 414-415.

Wilke, S., «Von angezogenen Affen und angekleideten Männern in Baja California: Zu einer Bewertung der Schriften Alexander von Humboldts aus postkolonialer Sicht», German Studies Review 34:2 (2011), 287-303.

Zantop, S., Colonial Fantasies. Conquest, Family, and Nation in Precolonial Germany, 1770-1870. Durham: Duke University Press 1997. 